EDITORIAL

\title{
Levels of explanation - symptoms, neuropsychological deficit and morphological abnormalities in schizophrenia ${ }^{1}$
}

Despite intensive research, schizophrenia continues to defy attempts to elucidate most aspects of its aetiology and pathophysiology. It is widely believed that the pathology of the disorder can only really be understood through a clarification of how its abnormalities at different levels interact with each other - the 'levels of understanding' model (see Frith, 1992; Mortimer, 1992). Symptoms, cognitive disorder, structural and/or functional brain pathology cannot be properly explained in terms of each other until consistent accounts can be provided of the abnormalities that are to be found at each of these levels. It may then become possible to understand how abnormality at one level is associated with abnormalities at adjacent levels. Such a model could also have implications for the marked heterogeneity in schizophrenia. The level of explanation intermediate between symptoms and neuropathology is the psychological; this includes as an important component a variety of neuropsychological impairments which have recently been found to occur in schizophrenic patients. Which aspects of schizophrenia neuropsychology have the capability to connect neuroscience with phenomenology?

\section{OVERALL INTELLECTUAL DETERIORATION IN SCHIZOPHRENIA}

In the course of a review of 94 studies comparing the abilities of various groups of psychiatric patients on reasonably standard neuropsychological tests, Heaton et al. (1978) found that acute, mixed and chronic schizophrenics were increasingly difficult to distinguish from patients with organic brain disease. They were doubtful whether these deficits could be attributed to poor motivation or distraction due to thought disorder, and medication effects were not obviously responsible; they concluded that chronic schizophrenic patients appeared 'organic' on neuropsychological testing because 'a significant proportion of them are organic' - in fact they surmised that this must be due to marked levels of undiagnosed neurological disease among chronic schizophrenic patients. Subsequent studies have confirmed the view that schizophrenia is accompanied by some degree of compromise of general intellectual function, varying from a decline in intelligence through obviously poor neuropsychological test performance (Kolb \& Whishaw, 1983; Nelson et al. 1990; Frith et al. 1991) to, in a small minority of patients, the levels seen in dementia (Owens \& Johnstone, 1980; Liddle \& Crow, 1884).

Can this finding be related to brain pathology? One relatively large study comparing cognition with CT scans found scores on the Luria-Nebraska neuropsychological battery correlated with ventricular brain ratio at 0.76 (Golden et al. 1982). Another larger study, however, found no relationship - or rather a complex relationship with an excess of cognitively impaired patients at both ends of distribution of lateral ventricular size (Owens et al. 1985). When Lewis (1990) reviewed the literature on this point he came to the conclusion that the association had more positive than negative replications, but that the nature and extent of the impairment tended to vary from study to study. At present, no findings exist relating general cognitive impairment in schizophrenia to functional imaging. This is a surprising omission from the literature.

These findings certainly add weight to the widely held view that schizophrenia is a biological brain disease. Unfortunately, since something closely resembling dementia supervenes in some previously

1 Address for correspondence: Dr A. Mortimer, West London Healthcare NHS Trust, Uxbridge Road, Southall, Middlesex, UB1 3 EU. 
intact patients it runs counter to another widely held view that the brain disorder of schizophrenia is neurodevelopmental rather than neurodegenerative (Murray et al. 1988; Lewis, 1989; Mednick \& Cannon, 1991). One study (Goldberg et al. 1988) found that age disorientation, an indicator of very severe cognitive decline, was invariably associated with ventriculomegaly. Alternatively, Purohit et al. (1993) studied 550 elderly institutionalized schizophrenic patients and found that twothirds of them were demented. Despite this, post-mortem studies on 13 of these demented patients failed to show that any of them fulfilled neuropathological criteria for Alzheimer's disease (Khachaturian, 1985). In addition, the morphological features of other dementing neurodegenerative conditions including multi-infarct dementia, Parkinson's disease, diffuse Lewy body disease, Creutzfeldt-Jakob disease and Pick's disease, were not encountered. The authors concluded that there was no evidence of independent dementia pathology in these patients - their gross cognitive impairment was not caused by 'dementia' but by schizophrenia. In view of these findings, the assumption that intellectual deterioration in schizophrenia is related to structural abnormalities may perhaps deserve re-examination; it may be that some other process, perhaps neurochemical, underlies the impairment.

Can intellectual deterioration in schizophrenia be related to symptomatology? Nelson et al. (1990) showed that a substantial IQ decline seen in long-stay patients related to phenomenology in that the worst affected patients had the least positive symptoms. Frith et al. (1991) identified a group of schizophrenic patients with low pre-morbid IQ and major IQ decline. Negative symptoms were associated with these deficits, as were male sex, a history of birth problems and longer in-patient stay. A number of other studies have found correlations between intellectual impairment in schizophrenia and negative symptoms. However, these have been argued to be an artefact of the joint association of these variables with general factors such as severity and chronicity of illness (see Mortimer et al. 1990 for a discussion of this).

\section{EXECUTIVE ('FRONTAL') DEFICITS}

Although a decline in IQ may be evident, the vast majority of patients with schizophrenia do not show any clinically obvious general intellectual impairment. Over the past 10 years, it has gradually become apparent that some of these patients do, however, show evidence of specific neuropsychological deficits. The most intensively investigated domain of function has been executive ('frontal') function, poor performance on one or more tests of which has been found repeatedly (Goldberg et al. 1987; Morice, 1990; Liddle \& Morris, 1991). Goldberg et al. (1987) strikingly demonstrated that this impairment was not artefactual by showing that patients' performance on the Wisconsin Card Sorting Test could be improved by giving explicit instructions of what to do; even then the improvement did not persist. The presence of widespread deficits in executive function has been confirmed in schizophrenia using the single case study approach currently the preferred methodology in cognitive neuropsychological research (Shallice et al. 1991).

At present, there is very little to suggest that executive impairment in schizophrenia is associated with structural brain abnormalities e.g. of the frontal lobes. Here, however, functional imaging has come into its own. Using activation with the Wisconsin Card Sorting Test, thought to tap frontal function, Weinberger et al. (1986) claimed to find a failure to activate prefrontally in patients versus controls, although numbers were relatively small and the overlap relatively large. Despite this a correlation between test score and activated frontal blood flow of 0.52 was found in patients but not controls, suggesting that patients' performance does depend to an extent on failure to activate. Subsequent replications of this study (e.g. Andreasen et al. 1992; Lewis et al. 1992) have found hypofrontality on executive task activation.

Can this impairment be related to symptoms? This is certainly an attractive idea. Liddle (1987) noted that some patients with frontal lobe lesions may show abnormalities reminiscent of schizophrenic lack of volition (the 'pseudodepression' syndrome of Blumer \& Benson, 1975), while others show phenomena not dissimilar from inappropriate affect and formal thought disorder (Blumer \& Benson's 'pseudopsychopathic' syndromes). A number of formal theoretical accounts 
have invoked an impairment in executive and/or frontal lobe function to explain negative symptoms (Frith, 1987), formal thought disorder (McKenna, 1987; McGrath, 1991) and certain other symptoms, especially alienation symptoms like thought insertion and passivity (Frith, 1987). Unfortunately, despite the intuitive appeal of this approach, the available empirical findings have provided little support for an association between impairment on executive tests and negative symptoms or formal thought disorder (Morrison-Stewart et al. 1992; Bentham et al. 1994). There may, however, be some evidence linking a particular cognitive function which is perhaps best understood as executive in nature to one class of schizophrenic symptom. Frith \& Done (1989) found that patients experiencing first-rank symptoms were impaired on a task requiring them to monitor their own self-generated actions; patients not currently experiencing such symptoms did not show this abnormality. This finding has recently been replicated (Mlakar et al. 1994).

\section{MEMORY DEFICITS}

McKenna et al. (1990) presented evidence that memory impairment in schizophrenia was prevalent, often substantial and disproportionate to the overall level of intellectual impairment. The deficits they found were not easily attributable to poor cooperation, attention or motivation, neither were they related to neuroleptic nor anticholinergic medication. Similar memory deficits were found by Saykin et al. (1991) who found memory performance stood out as impaired over and above a background of generally poor performance in medication-free schizophrenic patients.

Can this impairment be related to brain abnormality? Tamlyn et al. (1992) found that schizophrenic memory impairment resembled the pattern seen in the classic amnesic syndrome i.e. that seen in Korsakov's syndrome or following bilateral hippocampal damage. Saykin et al. (1991) similarly argued that the schizophrenic pattern of neurological impairment pointed to underlying temporo-hippocampal dysfunction. However, while neuropsychology has been conspicuously successful in showing that localized brain lesions are associated with impairments on specific cognitive tests, the converse, that specific impairments imply localized brain lesions, is almost certainly not true. For instance, memory impairment closely similar to the classic amnesic syndrome can be seen after frontal lobe lesions (Baddeley \& Wilson, 1986), and may also, with only minor differences, follow far from circumscribed brain damage as a result of closed head injury (Baddeley et al. 1987). Even so, the resemblance to the classic amnesic syndrome suggests that memory disorder in schizophrenia may hold promise as a localizer of specific brain disease rather than just reflecting generalized disease.

Can memory impairment be related to the symptoms of schizophrenia? Although the study of Tamlyn et al. found evidence of correlations between memory impairment and formal thought disorder, this has not been found in our subsequent replications (also, Duffy \& O'Carroll, 1994).

The memory deficit of schizophrenia appears to be restricted to long-term declarative memory (Clare et al. 1992; Tamlyn et al. 1992). While one broad division of declarative memory, episodic memory (memory for personal events such as what one had for breakfast) does not obviously assist the interpretation of any schizophrenic phenomena, the other, semantic memory, might have more explanatory power. Semantic memory is the store for all knowledge - of words and their meanings, concepts and facts. Because semantic memory refers essentially to the individual's information about the world, the finding of an impairment might offer a way to begin to understand key clinical features like delusions, hallucinations and formal thought disorder. To be deluded means nothing more or less than to 'know' (i.e. to believe) things which are patently not true. Schizophrenic patients with hallucinations also 'know' (i.e. are convinced that) their abnormal perceptual experiences are real; this is in contrast to patients with disorders like tinnitus, phantom-limb syndrome and epilepsy, who have equally compelling abnormal perceptions but have no difficulty in dismissing them as illusory. A distortion of concepts, meanings of words, and even word choice itself seems singularly well placed to account for the symptom class of formal thought disorder, where speech becomes difficult to make sense of and in which dysphasia-like abnormalities have been documented in severe cases (Faber et al. 1983). Frith (1992) has argued that many 
schizophrenic symptoms can be understood in terms of a fundamental disorder of 'second order' representations of knowledge, or knowledge about the world which is independent of personal experience. The ideas of second order, or 'meta-' representations of knowledge, and of knowledge in pure form held in semantic memory, seem to be in many ways similar.

\section{CONCLUSION}

The key proposition of the 'levels of explana' understand the disorder as it presents clinically $i$ causes it will always be an exercise in futility. $T$ as some older ones) e.g. that formal thought dis the left posterior superior temporal gyrus (S) correlated with the size of the third ventricle (C. the neuropsychological to the symptomatic : anatomical can, according to the levels of pro zophrenia is that to try to ifunction which presumably $r$ of recent findings (as well rrelated with the volume of nd that hallucinations are )). Even extrapolating from ychological to the neuroazardous. Such a view has obvious implications for the interpretation of studies (e.g. Gruzelier et al. 1988; Saykin et al. 1991), which claim to have found evidence of frontal, temporal and/or hippocampal abnormalities in schizophrenic patients on the basis of neuropsychological test findings. It even suggests that when functional imaging is performed alongside neuropsychological testing in schizophrenia, caution needs to be exercised in interpreting the results. Perhaps limited inferences about the relationship between adjacent levels can be drawn, but rules for this have yet to be articulated.

It is interesting to note, however, that considerable evidence implicates the left temporal lobe in semantic memory, this also being a site increasingly implicated as structurally and perhaps functionally abnormal in schizophrenia. Could these abnormalities extend to its connectivity with the frontal cortex and its executive functions, similarly incriminated in schizophrenia?

Such conjectures add little to the 'levels of understanding' model, but it is through speculation on these findings that testable hypotheses will be generated. The objective must be to transform the model, from its basis of intuitive, empirical 'understanding', to a basis of scientific solution. The transformed model would consist of levels of explanation, not understanding, thereby resembling physical more than mental disease. To demonstrate schizophrenia in this light could not harm the status of its sufferers, and may lead to improvements in their recognition and treatment.

ANN M. MORTIMER AND PETER J. MCKENNA

\section{REFERENCES}

Andreasen, N. C., Resai, K., Alliger, R., Swayze, V. W., Flaum, M., Kirchner, P., Cohen, G. \& O'Leary, D. S. (1992). Hypofrontality in neuroleptic naive patients and in patients with chronic schizophrenia. Archives of General Psychiatry 49, 943-958.

Baddeley, A. \& Wilson, B. A. (1986). Amnesia, autobiographical memory and confabulation. In Autobiographical Memory (ed. D. Rubin), pp. 225-252. Cambridge University Press: New York.

Baddeley, A., Harris, J., Sunderland A., Watts, K. P. \& Wilson, B. A. (1987). Closed head injury and memory. In Recovery from Head Injury (ed. H. S. Levin, J. Grafman and H. M. Eisenberg), pp. 295-317. Oxford University Press: New York.

Bentham, P., McKay, A. P., Shallice, T., Burgess, P., Lund, C. E., Quemada, J. I., Holbery, A., Mortimer, A. M. \& McKenna, P. J. (1994). The dysexecutive syndrome in schizophrenia: a group neuropsychological study. (In preparation.)

Blumer, D. \& Benson, D. F. (1975). Personality changes with frontal lobe lesions. In Psychiatric Aspects of Neurologic Disease (ed. D. Blumer and D. F. Benson), pp. 151-170. Grune \& Stratton: New York.

Clare, L., McKenna, P. J., Mortimer, A. M. \& Baddeley, A. D.
(1992). Preserved procedural and implicit memory in schizophrenia - further evidence for an amnesic syndrome pattern of impairment. Schizophrenia Research 6, 156.

Cullberg, J. \& Nyback, H. (1992). Persistent auditory hallucinations correlate with size of the third ventricle in schizophrenic patients. Acta Psychiatrica Scandinavica 86, 469-472.

Duffy, L. \& O'Carroll, R. (1994). Memory impairment in schizophrenia: a comparison with that observed in the alcoholic Korsakoff syndrome. Psychological Medicine 24, 155-165.

Faber, R., Abrams, R., Taylor, M. A., Kasprison, A., Morris, C. \& Weisz, R. (1983). Compariscn of schizophrenic patients with formal thought disorder and neurologically impaired patients with aphasia. American Journal of Psychiatry 140, 1348-1351.

Frith, C. D. (1987). The positive and negative symptoms of schizophrenia reflect impairments in the perception and initiation of action. Psychological Medicine 17, 631-648.

Frith, C. D. (1992). The Cognitive Neuropsychology of Schizophrenia. Lawrence Erlbaum: Hove, Sussex.

Frith, C. D. \& Done, D. J. (1989). Experiences of alien control in schizophrenia reflect a disorder in the central monitoring of action. Psychological Medicine 19, 359-363.

Frith, C. D., Leary, J., Cahill, C. \& Johnstone, E. C. (1991). Performance on psychological tests: demographic and clinical 
correlates of the results of these tests. British Journal of Psychiatry 159. (suppl. 13), 26-29.

Goldberg, T. E., Weinberger, D. R., Berman, K. F., Pliskin, N. H. \& Podd, M. H. (1987). Further evidence for dementia of prefrontal type in schizophrenia? Archives of General Psychiatry 44, 1008-1014.

Goldberg, T. E., Kleinman, J. E., Daniel, D. G., Myslobodsky, M. S., Ragland, J. D. \& Weinberger, D. R. (1988). Dementia praecox revisited: age disorientation, mental status and ventricular enlargement. British Journal of Psychiatry 153, 187-190.

Golden, C. J., McInnes, W. D., Ariel, R. N., Ruedrich, S. L., Chu, C-C., Coffman, J.A., Graber, B. \& Bloch, S. (1982). Crossvalidation off the ability of the Luria-Nebraska neuropsychological battery to differentiate chronic schizophrenics with and without ventricular enlargement. Journal of Consulting and Clinical Psychology 50, 87-95.

Gruzelier, J., Seymour, K., Wilson, L., Jolley, A. \& Hirsch, S. R. (1988). Impairments of neuropsychological tests of temporohippocampal and frontohippocampal functions and word fluency in remitting schizophrenia and affective disorders. Archives of General Psychiarry 45, 623-629.

Heaton, R. K., Baade, L. E. \& Johnson, K. L. (1978). Neuropsychological test patterns associated with psychiatric disorders in adults. Psychological Bulletin 85, 141-162.

Khachaturian, Z.S. (1985). Diagnosis of Alzheimer's disease. Archives of Neurology 42, 1097-1105.

Kolb, B. \& Whishaw, I. Q. (1983). Performance of schizophrenic patients on tests sensitive to right or left frontal, temporal or parietal function in neurological patients. Journal of Nervous and Mental Disease 171, 435-443.

Lewis, S. W. (1989). Congenital risk factors for schizophrenia. Psychological Medicine 19, 5-13.

Lewis, S. W. (1990). Computerised tomography in schizophrenia 15 years on. British Journal of Psychiarry 157, (suppl. 9), 16-24.

Lewis, S. W., Ford, R. A., Syed, G. M., Reveley, A. M. \& Toone, B. K. (1992). A controlled study of ${ }^{0 m}$ Tc-HMPAO single photon emission imaging in chronic schizophrenia. Psychological Medicine 22. 27-35.

Liddle, P. F. (1987). Schizophrenic syndromes, cognitive performance and neurological dysfunction. Psychological Medicine 17, 49-57.

Liddle. P. F. \& Crow. T. J. (1984). Age disorientation in chronic schizophrenia is associated with global intellectual impairment. British Journal of Psychiatry 144, 193-199.

Liddle. P. F. \& Morris, D. L. (1991). Schizophrenic syndromes and frontal lobe performance. British Journal of Psychiatry 158, 340-345.

McGrath, J. (1991). Ordering thoughts on thought disorder. British Journal of Psychiatry 158, 307-316.

McKenna, P. J. (1987). Pathology, phenomenology and the dopamine hypothesis of schizophrenia. British Journal of Psychiatry 151, 288-301.

McKenna, P. J., Tamlyn, D., Lund, C. E., Mortimer, A. M., Hammond, S. \& Baddeley, A. D. (1990). Amnesic syndrome in schizophrenia. Psychological Medicine 20, 967-972.

Mednick, S. \& Cannon, T. D. (1991). Fetal development, birth and the syndromes of schizophrenia. In Fetal Neural Development and
Adult Schizophrenia (ed. S. Mednick, T. D. Cannon, C. E. Barr \& M. Lyon), pp. 3-13. Cambridge University Press: Cambridge.

Mlakar, J., Jensterle, J. \& Frith, J. (1994). Central monitoring deficiency and schizophrenic symptoms. Psychological Medicine 24, 557-564.

Morice, R. (1990). Cognitive inflexibility and pre-frontal dysfunction in schizophrenia and mania. British Journal of Psychiatry 157, 50-54.

Morrison-Stewart, S. L., Williamson., P. C., Corning, W. C., Kutcher, S. P., Snow, W. G. \& Merskey, H. (1992). Frontal and non-frontal neuropsychological test performance and clinical symptomatology. Psychological Medicine 22, 353-359.

Mortimer, A. M. (1992). Phenomenology. Its place in schizophrenia research. British Journal of Psychiatry 161, 293-298.

Mortimer, A. M., Lund, C. E. \& McKenna, P. J. (1990). The positive:negative dichotomy in schizophrenia. British Journal of Psychiatry 157, 41-50.

Murray, R. M., Lewis, S. W., Owen, M. J. \& Foerster, A. (1988). The neurodevelopmental origins of dementia praecox. In Schizophrenia: The Major Issues (ed. P. Bebbington and P. McGuffin), pp. 90-106. Heinemann/Mental Health Foundation: Oxford

Nelson, H. E., Pantelis, C., Carruthers, K., Speller, J., Baxendale, S. \& Barnes, T. R. E. (1990). Cognitive functioning and symptomatology in chronic schizophrenia. Psychological Medicine 20 357-365.

Owens, D. G. C. \& Johnstone, E. C. (1980). The disabilities of chronic schizophrenia: their nature and the factors contributing to their development. British Journal of Psychiatry 136, 384-393.

Owens, D. G. C., Johnstone, E. C. \& Crow, T. J. (1985). Lateral ventricular size in schizophrenia: relationship to the disease process and its clinical manifestations. Psychological Medicine 15 27-41.

Purohit, D. P., Davidson, M., Perl, D. P., Powchik, P., Haroutunian, V. H., Bierer, L. M., McCrystal, J., Losonczy, M. \& Davis, K. L. (1993). Severe cognitive impairment in elderly schizophrenic patients: a clinicopathological study. Biological Psychiatry 33, 255-260.

Saykin, A. J., Gur, R. C., Gur, R. E., Mozley, P. D., Mozley, L. H., Resnick, S. M., Kester, B. \& Stafiniak, P. (1991). Neuropsychological function in schizophrenia. Archives of General Psychiatry 48, 618-624.

Shallice, T., Burgess, P. W. \& Frith, C. D. (1991). Can the neuropsychological case study approach be applied to schizophrenia? Psychological Medicine 21, 661-673.

Shenton, M. E., Kikinis, R., Jolesz, F. A., Pollak, S. D., LeMay, M., Wible, C. G., Hokama, H., Martin, J., Metcalf, D., Coleman, M. \& McCarley, R. W. (1992). Abnormalities of the left temporal lobe and thought disorder in schizophrenia: a magnetic resonance imaging study. New England Journal of Medicine 327, 604-612.

Tamlyn, D., McKenna, P. J., Mortimer, A. M., Lund, C. E., Hammond, S. \& Baddeley, A. D. (1992). Memory impairment in schizophrenia: its extent, affiliations and neuropsychological character. Psychological Medicine 22, 101-115.

Weinberger, M. D., Berman, K. F. \& Zec, R. F. (1986), Physiological dysfunction of dorsolateral prefrontal cortex in schizophrenia. Archives of General Psychiatry 43, 114-124. 